\title{
Social Media and Collective Remembrance
}

The debate over China's Great Famine on weibo

Hui Zhao and Jun Liu

\section{(2) OpenEdition}

\section{Journals}

Electronic version

URL: http://journals.openedition.org/chinaperspectives/6649

DOI: 10.4000/chinaperspectives.6649

ISSN: 1996-4617

\section{Publisher}

Centre d'étude français sur la Chine contemporaine

\section{Printed version}

Date of publication: 1 March 2015

Number of pages: 41-48

ISSN: 2070-3449

\section{Electronic reference}

Hui Zhao and Jun Liu, «Social Media and Collective Remembrance», China Perspectives [Online], 2015/1 | 2015, Online since 01 January 2017, connection on 28 October 2019. URL : http:// journals.openedition.org/chinaperspectives/6649; DOI : 10.4000/chinaperspectives.6649 


\title{
Social Media and Collective
}

\section{Remembrance}

\author{
The debate over China's Great Famine on weibo
}

\author{
HUI ZHAO AND IUN LIU
}

\begin{abstract}
This paper provides one of the first studies on the role of social media in articulating individuals' experiences and memories and (re-)shaping collective memory in contemporary China. It investigates how social media enable and facilitate the participation of ordinary citizens in distributing and accumulating alternative narratives and memories of the past against the authoritarian version by taking the debate over China's Great Famine - a topic long considered a political taboo - on Sina Weibo, one of the country's most popular social media sites, as the case study. This study demonstrates that weibo provides people with an alternative communicative sphere for sharing previously suppressed, marginalised, "unofficial" memories as civil disobedience and accumulating them into an alternative collective memory that is relevant to the changing socio-political context of China.
\end{abstract}

KEYWORDS: Collective memory, social media, alternative narrative, China, weibo, the Great Famine.

\section{Introduction}

W ith the growing popularity of Information and Communication Technologies (ICTS), new communication media such as the Internet, mobile phones, and social media are penetrating people's everyday lives and transforming the way they express themselves, interact with each other, articulate daily experience, and perceive the world. Beyond being merely a matter of technology, new media have become embedded in politics, the economy, culture, and social systems and are further shaping

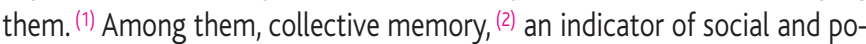
litical change, ${ }^{(3)}$ is one of reconfigurations under the influence of new media. As several studies demonstrate, the bottom-up, peer-to-peer, and horizontal communication enabled by low-end, easy-to-use, and networked communication technologies not only facilitates a continuous and accumulating memory, but also provides new opportunities for citizens to scrutinise and interrogate previous material archives as static memories, thus influencing how the past is remembered. (4)

This study takes weibo, China's microblogging services, as a case to investigate the impact of social media on the (re)formation of collective memory in contemporary China. China has the world's most active social media users. ${ }^{(5)}$ Ninety-five percent of Internet users in major cities are regular users of social media. ${ }^{(6)}$ Weibo is one of the most widely used social media in China. ${ }^{(7)}$ More than 290 million weibo users accounted for $45.9 \%$ of the total 632 million Chinese Internet users in 2014. ${ }^{\left({ }^{8}\right)}$ As an interactive and dynamic platform, weibo sees diversified voices and discourses from users from different backgrounds and social strata. ${ }^{\left({ }^{9}\right)}$ In particular, Chinese people's reliance on weibo as a platform for airing opinions, exposing discontent, criticising government policies, or venting anger over specific incidents is intensifying as the tightening of state control over mass media persists. ${ }^{(10)}$ Studies on weibo as a means of civic engagement and deliber-
An earlier version of this paper was presented in the conference "Complex Evolutions: Media and Democratization in Contemporary Asia" at St. Antony's college, Oxford University, United Kingdom, 5-6 September 2014. The authors are extremely grateful to the two anonymous reviewers from China Perspectives for their detailed and insightful suggestions, to Jingnan Zhou for her valuable comments and linguistic assistance, and to Dr. Tze-Luen Lin for his helpful feedback.

1. For instance, see Yochai Benkler, The Wealth of Networks: How social production transforms markets and freedom, New Haven, Yale University Press, 2006; Mark Deuze, Media Life, Cambridge, Polity, 2012; Harrison Rainie and Barry Wellman, Networked: The new social operating system, Cambridge, The MIT Press, 2012.

2. Maurice Halbwachs, On Collective Memory, trans. Lewis A. Coser, Chicago, University of Chicago Press, 1992; Jeffrey K. Olick, "Collective Memory: The two cultures," Sociological Theory, Vol. 17, No. 3, 1999, pp. 333-348.

3. For instance, on the changing perception of George Washington among Americans, see Barry Schwartz, "Social Change and Collective Memory: The democratization of George Washington," American Sociological Review, Vol. 56, No. 2, 1991, pp. 221-236; on the relationship between politics and collective memory, see Anita Shapira and Ora Wiskind-Elper, "Politics and Collective Memory: The debate over the 'New Historians' in Israel," History and Memory, Vol. 7, No. 1, 1995, pp. 9-40.

4. See, for instance, Motti Neiger, Oren Meyers, and Eyal Zandberg, On Media Memory: Collective memory in a new media age, New York, Palgrave Macmillan, 2011. José van Dijck, Mediated Memories in the Digital Age, Stanford, Stanford University Press, 2007. The special issue on "Digital media - social memory: Remembering in digitally networked times" by Media, Culture \& Society in September 2014.

5. Cindy Chiu, Davis Lin, and Ari Silverman, China's Social-Media Boom, 2012, www.mckinsey.com/insights/marketing_sales/chinas_social-media_boom (accessed on 15 August 2014).

6. Cindy Chiu et al., China's Social-Media Boom, op. cit., p. 1.

7. China Internet Watch, "Weibo Users vs. China Social-Media Users," 2014, www.chinainternetwatch.com/8675/weibos-social-media/ (accessed on 4 November 2014).

8. China Internet Watch, "Weibo Users vs. China Social Media Users" op. cit:; China Internet Network Information Center (CNNIC), "The 34th Statistical Report on Internet Development in China (July 2014)," 2014, www1.cnnic.cn/IDR/ReportDownloads/201411/P020141102574314897888.pdf (accessed on 4 November 2014).

9. For instance, see Adrian Rauchfleisch and Mike S. Schäfer, "Multiple public spheres of Weibo: A typology of forms and potentials of online public spheres in China," Information, Communication \& Society, Vol. 18, No. 2, 2014, pp. 139-155.

10. For instance, see Michael Chan et al., "Microblogging, Online Expression, and Political Efficacy Among Young Chinese Citizens: The moderating role of information and entertainment needs in the use of Weibo," Cyberpsychology, Behavior, and Social Networking, Vol. 15, No. 7, 2013, pp. 345-349; Jonathan Sullivan, "A Tale of Two Microblogs in China," Media, Culture \& Society, Vol. 34, No. 6, 2012, pp. 773-783; Jonathan Sullivan, "China's Weibo: Is faster different?", New Media \& Society, Vol. 16, No. 1, 2014, pp. 24-37. 
ation (11) and of mobilisation of political contention (12) have consequently flourished. Nevertheless, a relatively large amount of research so far focuses exclusively on the analysis of contemporary, discrete online contentious events, ${ }^{(13)}$ without scrutinising the political influence of weibo on a larger living context - among others, a society's collective memory - beyond a simple realisation of overt contentious possibility.

This study aims to fill this gap by exploring the influence of weibo on collective memory. More specifically, we ask: how does weibo provide a platform to articulate people's previous experiences and memories and further (re)shape collective memory in contemporary China? We first provide a critical review of current studies on collective memory and media, addressing the relevance of approaching such a topic from the perspective of social media - weibo in this study. Second, we briefly elaborate on methodological issues, followed by an overview of the selected case: the debate over "The Three-Year Great Chinese Famine" (hereafter "the Great Famine") on weibo. Given the fact that "the Great Famine" remains politically taboo ${ }^{(14)}$ and that there are complicated mechanisms of censorship on weibo to eliminate or restrict discussion of politically taboo topics, ${ }^{(15)}$ it is a bit surprising to us that weibo services have not completely blocked or censored tweets containing keywords such as "the Great Famine." In other words, one can still search for and read tweets containing "the Great Famine." We do not know the reason for this, however. ${ }^{(16)}$ Third, we scrutinise how weibo provides an opportunity for ordinary people to articulate and disseminate their alternative narratives of memories that previously had never been publicly acknowledged, in particular those that had been marginalised, excluded, or subjected to "forced amnesia" by the authorities. We argue that the articulation, accumulation, and dissemination of experiences and memories on weibo engender counter- and alternative narratives that contest the official framework of memory, reshape collective memory of the famine, and thereby generate a long-term influence on society. We conclude with thoughts on the political influence and implications of weibo on the reconstruction of collective memory in contemporary China.

\section{New media and collective memory: $A$ research agenda}

As the first scholar to use the term "collective memory," French philosopher and sociologist Maurice Halbwachs developed the foundational framework for the study of societal remembrance. ${ }^{(17)}$ Collective memory represents society's understanding of its past, defines the relationships between the individual and society, and allows the community to preserve its self-image and to transfer it through time. However, as Halbwachs observes, "Collective memory must be distinguished from history." (18) Instead, it is "essentially a reconstruction of the past in the light of the present." (19) Halbwachs's works explore how the present situation affects the selective perception of history. ${ }^{(20)}$ In his work On Collective Memory (Les cadres sociaux de la mémoire), Halbwachs differentiates collective memory from "social frameworks for memory," emphasising that "it is to the degree that our individual thought places itself in these frameworks and participates in this memory that it is capable of the act of recollection." (21) Halbwachs claims that, as a socially constructed notion, individual memory is constructed within social structures and institutions. More specifically, individuals organise and understand events and concepts within a social context. They then remember them in a way that "rationally" orders and organises them through that same social construction, or "social framework for memory." (22)
Later scholars advanced Halbwachs's work in various ways to elucidate the relations between social context and (re)construction of collective memory. Among them, Nora expands upon Halbwachs's discussion by recognising that groups select certain dates and people to commemorate, deliberately eliminate others from representation, and invent traditions and norms to preserve and support a specific collective memory. ${ }^{(23)}$ Nora observed that the representations of collective memory are those that have been specifically selected by people in power. In this sense, collective memory becomes both a tool and an object of power. Like Halbwachs, Nora suggests that the "collective memory" of any group is a manipulated construction by those who maintain the power and status to define those memories.

Although political power exerts considerable influences on the framing of collective memory, as Steiner and Zelizer point out, collective memory is a process that is constantly unfolding, changing, and transforming. Neither linear nor logical, the process of shaping collective memory is instead "dynamic and unexpected." (24) Social, political, and cultural factors engage in the negotiation of collective memory in which different stories and narratives compete for a place in the reconstruction of the past. ${ }^{(25)}$

Among many factors, media, in particular new media, play an emerging role in the process of shaping and formatting collective memory. ${ }^{(26)}$ The

11. For instance, Jonathan Hassid, "Safety Valve or Pressure Cooker? Blogs in Chinese political life," Journal of Communication, Vol. 62, No. 2, 2012, pp. 212-230; Adrian Rauchfleisch and Mike S. Schäfer, "Multiple public spheres of Weibo: A typology of forms and potentials of online public spheres in China," art. cit.

12. For instance, see Ronggui Huang and Xiaoyi Sun, "Weibo Network, Information Diffusion and Implications for Collective Action in China," Information, Communication \& Society, Vol. 17, No. 1, 2014, pp. 86-104; Thomas Poell, Jeroen de Kloet, and Guohua Zeng, "Will the Real Weibo Please Stand Up? Chinese online contention and actor-network theory," Chinese Journal of Communication, Vol. 7, No. 1, 2014, pp. 1-18.

13. For instance, on the train crash in Wenzhou in 2013, see Maria Bondes and Günter Schucher, "Derailed emotions: The transformation of claims and targets during the Wenzhou online incident," Information, Communication \& Society, Vol. 17, No. 1, 2014, pp. 45-65.

14. For instance, see Yang Jisheng, "China's Great Shame," The New York Times, 14 November 2012, p. A29.

15. See, for instance, David Bamman, Brendan O'Connor, and Noah Smith, "Censorship and Deletion Practices in Chinese Social Media," First Monday, Vol. 17, No. 3, 2012.

16. It is also beyond the aim of this article to discuss censorship on weibo.

17. Maurice Halbwachs, On Collective Memory, op. cit.

18. Ibid., p. 22.

19. Ibid., p. 34.

20. Barry Schwartz, Yael Zerubavel, and Bernice M. Barnett, "The Recovery of Masada: A study in collective memory," The Sociological Quarterly, Vol. 27, No. 2, 1986, pp. 147-164.

21. Maurice Halbwachs, On Collective Memory, op. cit., p. 38.

22. For instance, see John Bodnar, Remaking America: Public Memory, Commemoration, and Patriotism in the Twentieth Century, Princeton, Princeton University Press, 1992; Barry Schwartz, "The Reconstruction of Abraham Lincoln," In David Middleton and Derek Edwards (eds), Collective Remembering, Newbury Park, Sage, 1990, pp. 81-107.

23. Pierre Nora, "The Era of Commemorations," trans. Arthur Goldhammer, in Pierre Nora and Lawrence D. Kritzman (eds), Realms of Memory: The construction of the French Past, Volume III, New York, Columbia University Press, 1996.

24. Linda Steiner and Barbie Zelizer, "Competing Memories: Reading the past against the grain: The shape of memory studies," Critical Studies in Mass Communication, Vol. 12, No. 2, 1995, pp. 213239. Also see Iwona Irwin Zarecka, Frames of Remembrance: The dynamics of collective memory, New Brunswick, NJ, Transaction Publishers, 1994.

25. Marita Sturken, Tangled memories: The Vietnam War, the AIDS epidemic, and the politics of remembering, Oakland, University of California Press, 1997, p. 1. Also see Jens Brockmeier, "Remembering and Forgetting: Narrative as cultural memory," Culture \& Psychology, Vol. 8, No. 1, 2002, pp. 15-43; Joseph T. Coyle and Daniel L. Schacter, Memory Distortion: How minds, brains, and societies reconstruct the past, Cambridge, Harvard University Press, 1997.

26. Wulf Kansteiner, "Finding Meaning in Memory: A methodological critique of collective memory studies," History and Theory, Vol. 41, No. 2, 2002, pp. 179-197; Wulf Kansteiner, "Memory, media and Menschen: Where is the individual in collective memory studies?", Memory Studies, Vol. 3, No. 1, 2010, pp. 3-4; Mikyoung Kim and Barry Schwartz, Northeast Asia's difficult past: Essays in collective memory, New York, Palgrave Macmillan, 2010; Motti Neiger, Oren Meyers, and Eyal Zandberg, On Media Memory: Collective memory in a new media age, op. cit. 
availability and accessibility of new communication devices not only enable but also encourage alternative and counter narratives to emerge and proliferate against more official versions of history. (27) Social media, given its technological affordances of openness, accessibility, and interactivity, to mention just a few, emerge as a relevant channel for articulating, sharing, and disseminating narratives of the past. Nevertheless, very few studies so far have investigated the role of social media in (re)shaping social memory, leaving the field virtually unexplored. Similarly, in the case of China, existing studies keep their focus on weblogs, ${ }^{(28)}$ devoting less attention to the emerging role of weibo in (re-)shaping collective memory.

To fill this gap, this study explores the role of weibo for articulating people's memories and further (re)shaping collective memory in contemporary China. We take the debate over "the Great Famine" on weibo platforms to investigate:

RQ1: What kinds of counter- and alternative narratives of the past have been articulated and circulated through weibo?

RQ2: How are these narratives on weibo different from the official narrative, or the dominant social framework for memory of this specific period of the past?

RQ3: How and to what extent do the narratives of the past on weibo challenge or change collective memory in China?

To study the use of weibo and how weibo articulates people's memories and further (re)shapes collective memory through these uses, we present data collected through participant observation ${ }^{(29)}$ and immersion in the debate over "the Great Famine" on Sina Weibo, the most popular social media platform in China. This methodology can be described as ethnography in virtual worlds. ${ }^{(30)}$ More specifically, we "immersed" ourselves in this case by observing the start of the debate, monitoring it throughout the whole process (29 April to 2 May 2012), taking field notes about how people interacted and discussed this issue with each other, and recording - sometimes taking screenshots of - tweets in the debate hour by hour. ${ }^{(31)}$ We also "participated" in the discussion by marking the original and relevant tweets (e.g., those by weibo celebrities) as "favourite" and following the hashtag "\#the Great Famine" (\#dajihuang, \#大饥荒) on weibo in order to receive and retrieve the latest tweets under the hashtag even after the debate. Nevertheless, we did not engage in the discussion in order to leave the ongoing debate undisturbed and to avoid incorporating ourselves into the debate. Instead, we acted as a "lurker" to take participant observation and document the discussion. We also collected information from publications and media reports about "the Great Famine" as objects of analysis.

We then conducted analysis of data from weibo and traditional media. To work with participant observation data from weibo, specifically, we followed the guidelines of Boellstorff, Nardi, Pearce, and Taylor, (32) read the tweets, looked for core themes, categorised them, and highlighted key phrases and statements to identify explanations that illuminate the research question and develop new insights. We also integrated our field notes into the analysis. In short, the debate on weibo demonstrates a distinct disarticulation between individual narratives and the authorities' narratives of the past. Nevertheless, it is necessary to note that the case of the debate over "the Great Famine" is not intended as a representative sampling of political activities on weibo. Instead, the case highlights issues of special relevance for an understanding of the long-term influence of weibo on Chinese society beyond a simple realisation of overt contentious possibility.

\section{The debate over "the three-year Great Chinese Famine" on weibo}

The debate over "the Great Famine" on weibo platforms was triggered by Lin Zhibo, head of the Gansu Province branch of People's Daily (Renmin Ribao), the mouthpiece newspaper of the Chinese Communist Party (CCP). Having a verified account of his affiliation and more than 230,000 weibo followers, Lin questioned the multi-million death toll between 1960 and 1962 on his weibo account on 29 April 2012, asserting that the number was a conspiracy "to defile Chairman Mao by utilising the exaggerated slander of tens of millions of people dying of starvation." (33) According to Lin's tweet, "... locals only heard that people had died of starvation, but they had not personally witnessed any deaths from famine...very few people can be directly confirmed to have starved to death [in that era]." The claim that "millions died of starvation" was therefore fabricated to defame the leadership of Chairman Mao.

Lin's tweet quickly ignited outrage in the weibo community. Strong criticism was directed towards his denial of the starvation and deaths of millions in the early 1960s. The post was retweeted more than 7,000 times within four hours after it was first published, with the original post receiving more than 5,000 comments, most of which were scorching critiques. Lin had to shut down the reply function for this tweet. ${ }^{(34)}$ Trying to defend his viewpoint and to argue against weibo users who poured out their wrath and criticism towards his tweet, Lin responded with a string of somehow provocative questions, such as "... for those who heaped curses on me, tell me the person that died of starvation in your family during that period" [17:23, 29 April 2012], and "...so far none of you [who either retweeted my tweet or commented on it] have told me who starved to death in your families, yet all of you are declaring that there were millions of deaths [in that era]... If it were true, wouldn't that mean hundreds of millions dead?..." [17:40, 29 April 2012].

27. Michelle A. Amazeen, "The Politics of Memory: Contesting the 'Convention Night' version of this historic day," Media, Culture \& Society, Vol. 36, No. 5, 2014, pp. 679-690. Christian Pentzold and Vivien Sommer, "Digital Networked Media and Social Memory: Theoretical foundations and implications," Aurora. Revista de Arte, Mídia e Política, No. 10, 2011, pp. 72-85. Anna Reading, "Digital Interactivity in Public Memory Institutions: The uses of new technologies in Holocaust museums," Media, Culture \& Society, Vol. 25, No. 1, 2002, pp. 67-85

28. For instance, Guobin Yang, "A portrait of Martyr Jiang Qing: The Chinese Cultural Revolution on the Internet," in Ching Kwan Lee and Guobin Yang (eds), Re-envisioning the Chinese revolution: The politics and poetics of collective memories in reform China, Stanford, Stanford University Press, 2007, pp. 287-316; Lan Yang, "Memory and Revisionism: The Cultural Revolution on the Internet," in Ingo Cornils and Sarah Waters (eds), Memories of 1968: International perspectives, Oxford, Peter Lang AG, 2010, pp. 249-279; Junhua Zhang, "China's Social Memory in a Digitalized World: Assessing the Country's narratives in blogs," Journal of Historical Sociology, Vol. 25, No. 2, 2012, pp. 275-297.

29. Tom Boellstorff, Bonnie Nardi, Celia Pearce, and T. L. Taylor, Ethnography and Virtual Worlds: A handbook of method, Princeton, Princeton University Press, 2012, Chapter Five.

30. Boellstorff, Nardi, Pearce, and Taylor argue that labels such as "digital ethnography," "virtual ethnography," or "internet ethnography" are "...misleading overall because ethnographic methodology translates elegantly and fluidly to virtual worlds." See Tom Boellstorff, Bonnie Nardi, Celia Pearce, and T. L. Taylor, Ethnography and Virtual Worlds: A handbook of method, op. cit., p. 4.

31. We gathered the postings by using keywords search on Sina Weibo (including "Lin Zhibo," "the Great Famine," "The Three Years of Natural Disasters," and "The Three Years of Economic Difficulty").

32. Tom Boellstorff, Bonnie Nardi, Celia Pearce, and T. L. Taylor, Ethnography and Virtual Worlds: A handbook of method, op. cit., pp. 168-179.

33. Lin's message read: "Some people, to defile Chairman Mao, use the exaggerated slander of tens of millions of people dying of starvation between 1960 and 1962. And thus someone visited many of the villages in Henan and Anhui that were hardest-hit by the famine in those years, and the situation was nothing like what people slander it as. The locals had only heard of people dying of starvation, but had not personally witnessed any such deaths, and very few people can be directly confirmed to have starved to death." [14:17, 29 April 2012]; also see www.thechinastory.org/ archive/china-time/ (accessed on 15 August 2014).

34. Lin's message on 17:40, 29 April 2012. 
Probably to Lin's surprise, numerous weibo users did respond to his questions with various materials that demonstrated millions of deaths occurring in the early 1960s due to the famine. These materials included, among others, CCP archives and documents, government statistics, academic works, news reports, documentary films, and memoirs, stories, and memories about that period from their families.

Following such moves, Lin apologised on 30 April and 1 May, admitting that "...the population in 1960 shrank by 10 million as a result of the grave errors of the Great Leap Forward ${ }^{(35)}$ and the People's Commune Movement, (36) according to the conclusion given in 'The Seventy Year History of the Communist Party of China' (1991.8, first edition, p. 329)" (37) [20:40, 30 April 2012]. He also deleted the tweet that denied the famine mortality and replaced it with a more general apology ${ }^{(38)}$ that attributed his misguided remarks to a lack of awareness of that period. Lin's apology has been retweeted more than 23,000 times and has been commented on more than 17,000 times. Although Lin's apology overturned his denial of the deaths of the famine, the debate over "the Great Famine" continued. For one thing, Lin's apology kept drawing more criticism from weibo users, who questioned how someone like Lin, who majored in history as an undergraduate and who pursued further studies in Party and military history afterward, could be so ignorant of that era. ${ }^{(39)}$ For another, various activities related to the exploration of "the Great Famine" were being carried out not only on weibo but also in traditional media such as Southern People Weekly (Nanfang Renwu Zhoukan). Meanwhile, the controversy surrounding Lin never really subsided, either. One of the latest examples occurred in July 2014, when Lanzhou University in northwest China appointed Lin Zhibo dean of its journalism school. The decision sparked fierce discussions on weibo, where users immediately recalled the debate and subsequent criticism of Lin, centring on his denial of the existence of the Great Famine and the deaths in that part of Chinese history. ${ }^{(40)}$

\section{Findings}

During the debate over "the Great Famine," weibo provided a platform for ordinary people to engage in the collective remembering process, in which the articulation, dissemination, and aggregation of counter- and alternative historical narratives and memories emerged and proliferated, arguing against the official and orthodox version of the events from 1959 to 1961 in China. The intertwining of online and offline participation by people with and, more importantly, without weibo accounts revealed abundant historical material that was previously either unavailable to the public or banned from publication in the Chinese mainland due to the censorship. Many previously unknown individual memories and experiences about those three years finally came to light as the debate evolved.

\section{The dissemination and aggregation of counter- and alternative historical narratives}

When talking about the historical period of the People's Republic of China from 1958 to 1961, Chinese people often use the term "the Three Years of Economic Difficulty" (sannian jingji kunnan) or "the Three-year Natural Disaster" (sannian ziran zhaihai). This is largely due to the following two reasons: first, the description and conclusion in official discourse; and second, very limited information on the history of this period has been made available to the public. More specifically, people access information about this period through two channels: one is the historical textbook for compulsory courses in high school, which describes this period as "the Three Years of Economic Difficulty." (41) Never mentioning the death toll, this narrative attributes the fact of millions of people being wiped out by starvation to a series of natural disasters, such as drought and poor weather during that period. The textbook also talks about the Soviet Union's "perfidious" withdrawal of experts and technicians from China and its demands for payments for its industrial hardware, saying this exacerbated an already difficult situation and accelerated population loss. ${ }^{(42)}$ The other narrative is from History of the Chinese Communist Party, the official chronicle of the CCP, which claims "...serious natural disasters [in 1959] led to a decrease of over 30 million tons in food production...According to official statistics, the total national population in 1960 shrank 10 million from the preceding year" (emphasis added). ${ }^{(43)}$ To sum up, official and orthodox discourse about the historical period between 1959 and 1961 underlines unavoidable natural disasters and an external factor (the Soviet Union's withdrawal) as the only two reasons leading to the famine deaths. Meanwhile, the narratives remain very vague without mentioning any details about the famine. Also, the Chinese mass media have rarely touched on this topic due to its political sensitivity. ${ }^{(44)}$ These vague and unclear narratives make people refer to the historical period from 1959 to 1961 as a political taboo, (45) or a "dark chapter" (46) in the history of the CCP, which is strictly under the Party's control. In this sense, the debate over "the Great Famine" on weibo for the first time allowed the articulation and proliferation of counter- and alternative historical narratives about the historical period from 1959 to 1961 . Criticism of the official, orthodox narrative consequently emerged and has been disseminated to a wide extent. Generally speaking, weibo users engaged in the debate by contributing counter- and alternative historical narratives from two aspects. First is the authenticity of the famine. Lin's tweets called into question the very existence of the famine between 1959 and 1961. To respond to his doubt, weibo users, be they celebrities or ordinary people, engaged in articulating

35. The Great Leap Forward took place in 1958 as Mao's attempt to modernise China's economy. For more information, see Roderick MacFarquhar, The Origins of the Cultural Revolution (Vol. 3), Cambridge, Cambridge University Press, 1997. Zhihua Shen and Yafeng Xia, "The Great Leap Forward, the People's Commune and the Sino-Soviet Split," Journal of Contemporary China, Vol. 20, No.72, 2011, pp. 861-880.

36. The People's Commune movement tried to transform China quickly from a socialist system to a communist system; see Zhihua Shen and Yafeng Xia, "The Great Leap Forward, the People's Commune and the Sino-Soviet Split," op. cit.

37. This work offers the official history of the Chinese Communist Party.

38. Lin's tweet read, "I haven't done much research about the history of the Great Famine and didn't know much of it. In the past few days, I received a lot of messages from internet users describing their traumas at the time. I'm deeply shocked at what I've learned. My inappropriate words have triggered many people's painful memories and hurt many people's feelings. I feel very sorry and hereby apologise to everybody! Thanks to netizens for pointing out my mistakes. I hope we can work together to prevent such a tragedy from happening again." [10:14, 1 May 2012]

39. See, for instance,www.weibo.com/1956025337/ygWvJDdMX (accessed on 15 August 2014)

40. See, for instance, www.weibo.com/1802485367/Bd5/taofc (accessed on 15 August 2014).

41. History Section of People's Education Press, A Modern and Contemporary History of China (Volume II), Beijing, People's Education Press, 2003, p. 109.

42. History Section of People's Education Press, A Modern and Contemporary History of China, op. cit., pp. 109-110.

43. The Central Party History Research Office, History of the Chinese Communist Party (Volume II, 1949-1978), Beijing, Party History Press, 2011, pp. 368-369.

44. Although a few articles from, for instance, Yanhuang Chunqiu, a liberal-leaning monthly journal, covered this topic before the debate, the articles were still circulating within a very small circle and few people knew of them.

45. Tania Branigan, "China's Great Famine: The true story," 1 January 2013, www.theguardian.com/ world/2013/jan/01/china-great-famine-book-tombstone (accessed on 26 September 2014).

46. Junhua Zhang, "China's Social Memory in a Digitalized World: Assessing the country's narratives in blogs," art. cit., p. 284. 
and aggregating alternative stories, memoirs, and memories either from their own experiences or from those of family members. For instance,

@Lu Gongmin (weibo nickname): Between 1958 and 1960, my greatgrandmother, seven people in my grandparents' generation, and my aunt and my uncle, a total of ten people, starved to death one by one in Tongwei County, Gansu Province. [10:09, 1 May 2012]

@Coding worker Zhao Ye (weibo nickname, verified as a journalist): Just ended a call with my father, who mentioned that during the great famine period in the 1960 s...there were more than 100 people who died in our village...in Caohu Village, Anhui Province...@Lin Zhibo If Director Lin is interested, I can bring you to my hometown and carry out some interviews. People aged 60 years old or older there all have similar memories [of the great famine] during that period... [23:23, 1 May 2012]

People also circulated similar stories they read from different sources to prove the existence of "the Great Famine." For instance, quite a few weibo posts cited stories from Tombstone: An Account of Chinese Famine in the 1960s (hereafter Tombstone), (47) a government-banned reportage by Yang Jisheng, a retired journalist of the government-run Xinhua News Agency. For instance,

@HuoshanBaiyang (weibo nickname, verified as a journalist from the Xinhua News Agency): I was born in the mid-1970s...so I did not have any experience with the famine deaths in the 1960s. But my elders told me quite a few stories, and I also read Yang Jisheng's Tombstone. I believed what they said... [30 April 2012, 4:52]

Uncovering a series of colossal tragedies, including cases of cannibalism, and the continued systematic efforts of the party-state to cover up the history of the Great Famine, Tombstone has been banned in the Chinese mainland. Nevertheless, its influence has snowballed in the debate over "the Great Famine" on weibo.

Alternative historical narratives also came from memoirs by Party cadres. For instance, @QinglouZhishang (weibo nickname) quoted the memoir of veteran cadre Li Lei, then secretary of the Party committee of Linxia Prefecture, Gansu Province, in which Li revealed that "...588 people ate 337 bodies in 10 communes in Linxia City" during "the Great Famine." (48)

In addition to publishing these materials on their own weibo accounts, people also tweeted them to weibo celebrities with several millions of followers, such as Yu Jianrong (a professor at the Chinese Academy of Social Sciences with 1.8 million weibo followers) and Kai-Fu Lee (a Taiwanese IT entrepreneur with more than 51 million weibo followers), for further dissemination of these stories, memoirs, or statistics to a wider readership on the basis of their influence.

Second is the death toll during the famine. Again, weibo users collected various materials to argue against Lin's denial of the death toll. For instance, with more than 2 million weibo followers, economist Mao Yushi proposed his method of calculating the death toll and estimated a total of 36 million [19:56, 30 April 2012]. Historical scholar LeiYi, who has more than 270,000 followers, presented demographer Cao Shuji's article "The Great Famine: A demographic analysis of population in China between 1959 to 1961" and Dutch historian Frank Dikötter's book Mao's Great Famine: The History of
China's Most Devastating Catastrophe, 1958-62, which declare death tolls of 32.5 million and 45 million, respectively [9:19, 1 May 2012]. Writer Chen Lan also quoted statistics from two authoritative sources, The Cambridge History of China and History of the Chinese Communist Party, showing that the death toll would be either 37 million or 10 million.

In addition to "weibo celebrities," ordinary weibo users also offered statistics they read from academic and historical documents to back up their opinions about the death toll. Xiyue jianglang (weibo nickname), for instance, presented figures raised by American Sinologist Basil Ashton and Ansley J. Coale, former chair of the Population Association of America, a professional organisation devoted to population-related issues. According to his tweet, Ashton estimated that there were around "...30 million excess deaths and about 33 million lost or postponed births," while Coale believed the death toll was 27 million.

In short, alternative narratives and statistics about "the Great Famine" proliferated within only two days on weibo. These narratives or numbers from various sources not only argued against Lin's denial but also demonstrated a fundamentally different narrative of the historical period from that provided by the dominant official discourse and the prescribed social framework of memory. Be they celebrities with thousands of weibo followers or ordinary users, people worked together to articulate, disseminate, and forward these narratives, stories, memoirs, and statistics to a wider scope. Such sharing and distribution not only greatly shaped the online debate over the historical period but also gradually established the concept of "the Great Famine," which consequently replaced the term "the Three Years of Economic Difficulty" or "the Three-year Natural Disaster" in the discussion.

\section{The availability of previously inaccessible documents}

Weibo allows users to post and distribute information in various forms, such as text, photos, music, short videos, or a combination of multimedia content. Long-form content and links from other websites can also be embedded in a tweet. Posts on weibo therefore become content-rich, descriptive, and vivid. The technological affordances ${ }^{(49)}$ of weibo enabled participants in the debate to present an abundance of historical material covering the period from 1959 to 1961 by crowdsourcing. In particular, many historical archives and documentaries that were previously unavailable to the public, such as Party documents and archives, ${ }^{(50)}$ books that had been censored by the government, and overseas documentaries, accumulated on weibo and were exposed to the public for the first time to confirm the very existence of the famine.

Before the debate, few people had heard of Frank Dikötter's work (51) on the famine. After historian Lei Yi posted a photo of the cover of the tradi-

47. For the Chinese edition in Hong Kong, see Yang Jisheng, Mubei - Zhongguo liushi niandai da jihuang jishi (Tombstone: An account of Chinese Famine in the 1960s), Hong Kong, Cosmos, 2008; for English translation, see Yang Jisheng, Tombstone: The Great Chinese Famine, 1958-1962, trans. Stacy Mosher and Guo Jian, New York, Farrar, Straus and Giroux, 2012.

48. See more discussion on www.weibo.com/1782415244/yhbGrztXs\#_rnd1408436255362 (accessed on 15 August 2014).

49. Klaus Bruhn Jensen, Media Convergence: The three degrees of network, mass, and interpersonal communication, London, Routledge, 2010, p. 74.

50. For instance, for a copy of a "special report" by a central investigation group regarding the starvation deaths of more than 1,700 people in the Temple Zhao production brigade in Anhui Province from winter 1959 to summer 1960, see www.weibo.com/1687198333/ygSubmNrk\#_ rnd1408465965414 (accessed on 15 August 2014)

51. Frank Dikötter, Mao's Great Famine: The history of China's most devastating catastrophe, 19581962, London, Bloomsbury Publishing USA, 2010. 
tional Chinese translation of Dikötter's work published in Hong Kong, quite a few people followed him on weibo and asked where they could find this book. As soon as one of them replied that $s /$ he had an electronic version of this book, a lot of people sent their email addresses, asking for a copy of it. Similarly, weibo encouraged the dissemination of Yang's Tombstone, which was banned from publication in the mainland, allowing more people to read and share the tragedies of the famine.

On 1 May 2012, Charles Xue Biqun, a Chinese-American entrepreneur known by his weibo nickname "Xue Manzi" with more than 11 million followers, posted long-form content (as a picture) that compiled detailed discussion about "the Great Famine." The collection also included posts that had been deleted by Sina Weibo due to their political sensitivity. In this post, Xue ${ }^{(52)}$ encouraged people to take time to read this collection carefully, as "...tens of millions of people starved to death between 1959 and 1961." [10:18, 1 May 2012]

Given the unprecedented abundance of historical materials and archives generated by weibo users during and after the debate, Chinese writer Zhang Lifan established an online monument dedicated to the memory of the Great Famine. ${ }^{(53)}$

\section{The intertwining of online and offline participation}

Engagement in the debate over "the Great Famine" existed not only on the weibo platform, but also extended offline and then went back online. Specifically, weibo users moved offline to collect material about the famine and then shared these materials on weibo. In particular, this process features a specific intertwining of online and offline participation by people with and without weibo accounts - or even without Internet access.

Previous studies have already recognised that new communication technologies, including the Internet, mobile phones, and social media, allow people to participate in political debates or contentious activities both online and offline. ${ }^{(54)}$ In most current studies, participants are more or less correlated to contentious issues and engage in contention by utilising and manoeuvring ICT resources available to them. For instance, participants in ICT-mediated contention would be residents who utilise the Internet and mobile phones to argue against potentially detrimental petrochemical projects, ${ }^{(55)}$ or individuals or Non-Governmental Organisations (NGOs) who employed online forums to expose corruption or injustice that violates their interests. ${ }^{(56)}$ The participants in the debate over "the Great Famine" are rather different. Because most weibo users were born in the 1970s or 1980s, they have no direct experience with the famine in the 1960s, but could only gain knowledge of that period from textbooks. Nevertheless, during the debate they "went back" to the offline world, collected stories and memories from people they knew who suffered during the famine (most of them delved into their grandparents' past), and re-told their stories and memories via weibo. It is in this sense that people who experienced and survived the famine, even if they did not have weibo accounts or Internet access, were still able to participate in the debate, no matter how indirectly. Their stories and memories, previously largely unknown to the public, thereby became relevant evidence of the famine and became known to more people. For instance:

@Z Chunlei (weibo nickname): I was born in the 1980s, so I have no experience of the famine. However, my mother, who was born in the 1950s, often told me stories of starvation during that period [from
1959 to 1961]... The most impressive one is that a beggar asked my grandma for something to eat, which my grandma refused. The beggar kept on walking for less than 500 meters and then died at the entrance of the village.

@ BeiDafei (weibo nickname): My parents' hometown is located in the northern part of Suzhou City. I called them and asked whether there were people who died of hunger during the Great Famine. My father said that one hungry cousin came to visit his neighbour for something to eat. However, the neighbour did not have extra food to give him. After a few days, the cousin died of hunger. My mother said that quite a few children ate too much potherb and were poisoned to death, including a young daughter of her high school headmaster....

A lot of similar examples show that it was not only weibo users who joined the debate, but also their relatives and friends who experienced "the Great Famine" period but whose experiences, stories, and memories were unknown to others because they lacked weibo accounts or Internet access. In this way, the articulation of alternative narratives represents not only the experiences of weibo users, but more importantly, the experiences of people who lived through the period of 1959-1961 but never had the opportunity to tell their experiences and memories. These marginalised and suppressed experiences and memories have been disseminated for the first time through weibo, making them relevant to the social memory of the period of 1959-1961.

Moreover, the debate over "the Great Famine" moved from the online platform to offline media. Following the debate on the weibo platform, Southern People Weekly (Nanfang Renwu Zhoukan) devoted a special issue on 21 May 2012 to the topic "The Great Famine," a term that had never been used in the mass media to describe the period from 1959 to 1961. The issue included 18 pages of in-depth coverage, showing for the first time black-and-white photographs of sobbing, famished victims and of farmers gathering leaves and tree bark for food. More news reports about the famine emerged in mass media, revealing more stories and memories about this period. ${ }^{(57)}$

To sum up, the debate over "the Great Famine" on weibo characterises a specific type of engagement: people with and without weibo accounts

52. In late August 2013, Xue was put under administrative detention by Beijing police for allegedly hiring a prostitute. See David Barboza, "Chinese-American Commentator and Investor Is Arrested in Beijing," The New York Times, 5 August 2013, www.nytimes.com/2013/08/26/world/asia/chinese-american-commentator-and-investor-is-arrested-in-beijing.html?_r=0 (accessed on 11 December 2014).

53. "The online monument for the Great Famine" (previous link: http://t.cn/zOTAOt0 [accessed on 15 May 2014]), however, has been shut down by weibo service due to censorship.

54. Guobin Yang, "The Internet and Civil Society in China: A preliminary assessment," Journal of Contemporary China, Vol. 12, No. 36, 2003, pp. 453-475; Guobin Yang, "The Internet and the Rise of a Transnational Chinese Cultural Sphere," Media, Culture \& Society, Vol. 25, No. 4, 2003, pp. 469490; Guobin Yang, "Environmental NCOs and Institutional Dynamics in China," The China Quarterly, No. 181, 2005, pp. 46-66; Guobin Yang, The Power of the Internet in China: Citizen activism online, New York, Columbia University Press, 2009.

55. For instance, Jun Liu, "Mobile Communication, Popular Protests and Citizenship in China," Modern Asian Studies, Vol. 47, No. 3, pp. 995-1018; lan Weber, "The rise of China's middle-class civil society?", Critical Arts: South-North cultural and media studies, Vol. 25, No. 1, 2011, pp. 25-45.

56. Guobin Yang, "Environmental NCOs and Institutional Dynamics in China," art. cit.

57. For instance, see Zhongyu Li, "Huanxing zubei chenfeng de ji'e jiyi" (Wake up the dusty memory about hunger from our ancestry), 26 May 2013, http://bjyouth.ynet.com/3.1/1305/26/ 8034038.html (accessed on 26 September 2014); Mark Mackinnon, "Is China finally confronting its dark history?", 10 September 2012, http://m.theglobeandmail.com/news/world/worldview/ischina-finally-confronting-its-dark-history/article2445203/? service=mobile (accessed on 14 November 2014). 
"worked together" to crowdsource and contribute to the debate. The majority of people with access to weibo are too young to have any direct experience or memory of the famine, while those who experienced and survived the famine never had a chance to share their experiences and memories with other people or make them known to society. The collaboration between these two groups provided original and valuable accounts and memories of that period and accordingly deepened the debate over "the Great Famine." Without people with access to weibo, stories or memories of the famine may not have reached a wide audience. Similarly, without people sharing their individual experiences, memories, and stories about the famine, the debate would have lacked significant evidence. These personal experiences served as convincing evidence to prove to Lin that there were indeed deaths during the period of 1959-1961, as well as forming a shared memory that people felt an urge to let out. The intertwining of online and offline participation not only expanded the scale, scope, and depth of the debate, but also integrated fragmented and marginalised memories and experiences of the famine.

\section{Discussion}

In the debate over "the Great Famine," weibo functions as a relevant sphere that facilitates investigations of a history that was excluded, marginalised, or "forced to be forgotten" in China, generating reflections on the government's memory policy, articulating individuals' fragmented memories of the past and making them relevant to the society, and reshaping collective memory of the period from 1959 to 1961.

First, beyond verifying the existence of famine deaths and exact numbers, the debate further probes more politically sensitive questions such as the cause of the famine and the authenticity of its history. Although initially the debate focused on verifying the famine and its death toll, the discussion ventured beyond these two questions. Further questions emerged, such as, "How shall we evaluate the history of the famine and memorialise it fairly?", and more politically sensitive ones such as, "What was the actual cause of the famine?" For instance, people quoted Dutch historian Dikötter's work, which describes "the Great Famine" as "the worst catastrophe in China's history, and one of the worst anywhere." Beyond simply documenting stories about the famine, Yang's work Tombstone castigated the political system in China that caused millions of deaths within three years. Distinguished from the official narrative that blames either nature or the Soviet Union for the massive number of starvation victims, Yang underlines "the famine" as an "unnatural disaster." According to the investigation in Tombstone, the famine was caused neither by bad weather nor by the Soviet Union's treachery, but rather was a "man-made," political calamity "born [out] of the system of totalitarianism." (58) As such, alternative narratives of the famine, in particular those previously banned by the government and strongly critical of the political system under Mao's regime, proliferate via weibo, calling for people to reflect on totalitarian systems. Southern People Weekly, for instance, noted that "...we should never return to that political system [from 1959 to 1961]." These critiques and reflections not only shape people's perception and knowledge about the historical period of the famine, but also encourage them to rethink the current political system in China.

Meanwhile, the debate scrutinises and reflects upon China's memory policy by criticising and challenging the dominant social framework of memory regarding the period of 1959-1961. Accordingly, it calls for the government to face up to and respect the "dark chapters" of history, even if they belong to the most tragic period. The prescribed social framework of memory deliberately chooses to understate or even make no mention of famine deaths during the period of 1959-1961. It also places the blame squarely on either natural disaster or the Soviet Union. This framework largely shaped social memory of the period of 1959-1961, with the result that people either have never heard of "the Great Famine" or attribute it to inexorable reasons such as the weather. ${ }^{(59)}$ During the debate, people raised questions such as why the government prevented its people from knowing of the existence of the Great Famine and why the government has never wanted to face up to this disastrous historical incident. The outpouring of anger, distrust, and frustration on weibo towards the government's highly-controlled memory policy that aims to eliminate or rewrite dark chapters in the history of the CCP demonstrates a crisis of legitimacy regarding the dominance of the CCP's framework of memory. In its investigation, Southern People Weekly made a provocative statement, saying that "history [in China] is sometimes divided into two parts: history itself, and 'admitted history,'...The famine, which is unparalleled in human history, has neither an official record nor a reasonable explanation." The discussion in Southern People Weekly accordingly suggested that the government should "face up to history" and openly admit policy errors such as the Great Leap Forward and the establishment of the People's Communes. Most importantly, as the discussion highlights, the government should respect and memorialise the famine deaths rather than deliberately force society to forget them. The engagement of traditional media not only expands the influence of the debate on weibo by continuing investigation on the famine, but to a degree legitimates the use of the term "the Great Famine" in practice. In this sense, the debate over "the Great Famine" brings an opportunity to discuss politically sensitive topics and raise alternative discourse on social media platforms, which may have a long-term effect on government control over memory policy and the discussion of historical events.

Second, weibo provides a platform for Chinese people to articulate and share their individual memories that have never been accessible to the public or that have been marginalised, suppressed, or "forced to be forgotten" by the authority in its framework of memory. The dissemination and accumulation of these fragmented, individual memories on weibo have solidified into an alternative collective memory that argues against the official framework that deliberately "forgot" it. As we discussed earlier, the official narrative of the historical period in high school textbooks and Party historical archives never included details about the famine but just a few vague sentences. The debate on weibo, on the other hand, exemplifies detailed individual experiences and memories of this period and disseminates them to an unprecedented extent. These narratives of memories crystallise the history of the famine, introducing concrete human beings and their suffering into the vague official statements. As Halbwachs observes, "While the collective memory endures and draws strength from its base in a coherent body of people, it is individuals as group members who remember" (emphasis added). ${ }^{(60)}$ For individuals who survived the famine and for those who died of starvation, their experiences, including suffering and loss, that had never been mentioned by the authorities, have been recognised, communi-

58. Jonathan Mirsky, "Unnatural Disaster," The New York Times, 9 December 2012, www.nytimes.com/ 2012/12/09/books/review/tombstone-the-great-chinese-famine-1958-1962-by-yangjisheng.html? pagewanted=all\&_r=0 (accessed on 26 September 2014).

59. For instance, Lu Xiaoya, a teacher, reveals her shock when her students blurted out the term "Three-year Natural Disaster" to describe the period of 1959-1960. See www.weibo.com/1570831234/zqtZVkgwf (accessed on 26 September 2014).

60. Maurice Halbwachs, On Collective Memory, op. cit., p. 22. 
cated, and acknowledged by an increasing number of people. In this process, weibo users trace back into history and search for the names of each and every person who starved to death in order to remember them. Likewise, in this process of gathering evidence to authenticate the famine, individual experiences, especially in remote rural areas, have been collected, aggregated, and treated with respect.

All of this contributes to the process of recognition and reconstruction of collective memory of the famine. For instance, Lin admitted in his account that the collective effort of weibo users caused him to learn a lot about the devastating stories of the famine. ${ }^{(61)}$ An online survey was initiated after the debate to determine whether people believed in the 30 million death toll for the Great Famine period. By the time the survey ended on 10 May, more than 12,000 weibo users had participated in it and more than 5,000 users retweeted the result. Among them, 32.1\% believed there were more than 30 million deaths, or even 50 or 80 million, over those three years; $36.1 \%$ "firmly believed" that the death toll was 30 million; $24.5 \%$ thought the number was unreliable, and about $7.2 \%$ found it difficult to make a judgment. In other words, seven out of ten participants believed the conclusion that 30 million people - or even more - starved to death over those three years. The term "the Great Famine" is gradually replacing those used by the authorities to underline that this is period of history that should not be forgotten.

To sum up, in the debate over "the Great Famine," weibo functions as a sphere that, for one thing, invites its users to engage in deliberative discussions and investigations by crowdsourcing materials about the famine. For another, the weibo sphere generates, articulates, and integrates fragmented and disjointed individual memories and experiences into a shared, collective memory of the famine on one of the largest social media platforms in China, making it relevant to the majority of people in society. The ability of weibo to empower people to deliver and share their memories and experiences in a coherent manner underlies its power to generalise and unify collective memory and further organise the needs of the majority into politically relevant forms of consciousness and activity.

\section{Conclusion}

This paper provides one of the first studies on the role of social media in articulating individual memories and (re-)shaping collective memory in contemporary China. It investigates how weibo enables ordinary people to participate in distributing, interacting, and accumulating alternative narratives and memories of the past against the authoritarian version by engaging in debate over China's Great Famine - a topic long considered politically taboo - on Sina Weibo, one of the country's most popular social media sites, as a case study. As this study argues, weibo allows people to engage in active, professed activities to deliberately resist some form of perceived hegemony by the dominant discourse on history. This study demonstrates that weibo provides people with an alternative communicative sphere for sharing previously suppressed, marginalised, and "unofficial" memories as civil disobedience and accumulating them into an alternative collective memory that is relevant to the changing socio-political context of China.

\section{Looking beyond exceptional moments for long-term influence}

Quite a few studies have identified the political role of new communication technologies, including the Internet, mobile phones, and social media such as weibo, in facilitating political activism in a sort of remarkable moment. Compared with these remarkable moments and cases, the debate over "the Great Famine" on weibo did not last for a long period. Although the debate was triggered by a contemporary event, it still generated longterm political influence. Such long-term influence, we would argue, is largely based on the mundane use of social media, or what Bakardjieva refers to as "subactivism" (62) that has been incorporated into and reflected at the level of everyday use of new media. Even if such debate may not change, for instance, the content of high school textbooks or Party discourse on the Great Famine, it not only reveals the cumulative effects of ICTs and their "gradual revolution," (63) but also sheds light on the deeper impact of new communication technologies on social and political change in Chinese society today and in the years to come. It is in this sense that, using the debate over "the Great Famine" as a case study, we argue that Chinese people engage in a "long revolution" (64) through mundane media in everyday life for political change, no matter how small. In this sense, this study concludes that social media's democratising potential is not just in enabling and facilitating specific use in contentious moments, but more importantly embedded in routine use that articulates users' experiences and memories and further cultivates their political subjectivity. The study contributes to a comprehensive understanding of the democratising potential of social media beyond a simple realisation of contentious possibility, in particular how social media have been incorporated into the fabric of experience, nurturing resistance and disobedience, and facilitating an alternative public sphere. We also suggest more studies addressing the political dynamics embedded in the articulation and accumulation of experiences and memories by new media use and its long-term impact on politics, culture, and society.

\section{Hui Zhao is a PhD candidate in the Department of Strategic Communication at Lund University, Sweden. \\ Universitetsplatsen 2, P.O. Box 882, SE - 25108, Helsingborg, Sweden (hui.zhao@isk.lu.se).}

IJun Liu (corresponding author) is an assistant professor in the Department of Media, Cognition and Communication at University of Copenhagen.

Karen Blixens Vej 4, 2300 Copenhagen S, Denmark

(liujun@hum.ku.dk). 